\title{
(TA) UDP-Glucuronosyltransferase 1A1 Promoter Polymorphism in Nigerian Neonates
}

\author{
MICHAEL KAPLAN, TINA SLUSHER, PAUL RENBAUM, DOMINIC F. ESSIET, SUNDAY PAM, EPHRAT LEVY-LAHAD, AND \\ CATHY HAMMERMAN
}

\begin{abstract}
Department of Neonatology [M.K., C.H.], Medical Genetics Unit [P.R., E.L.-L.], Shaare Zedek Medical Center, Faculty of Medicine of the Hebrew University, Jerusalem 91031, Israel; Department of Pediatrics [T.S.], University of Louisville, Louisville, KY 40292; Department of Chemical Pathology [D.F.E.], Eku Baptist Hospital, Delta State University, Abraka 331001, Delta State, Nigeria; Jos University Teaching Hospital [S.P.], Jos 930001, Plateau State, Nigeria
\end{abstract}

\begin{abstract}
Nigerian neonates have a high incidence of bilirubin encephalopathy. Glucose-6-phosphate dehydrogenase (G-6-PD) deficiency is prevalent in this population. (TA) $)_{7}$ promoter polymorphism in the gene encoding the bilirubin conjugating enzyme UDP-glucuronosyltransferase 1A1 (UGT1A1) potentiates hyperbilirubinemia in G-6-PD deficient neonates. We studied (TA) allele frequency to determine, at least in part, its contribution to the frequency and severity of hyperbilirubinemia. DNA was extracted from umbilical cord blood of sequentially born Nigerian neonates and the (TA) $)_{n}$ UGT1A1 promoter sequence determined. The (TA) allele distribution was compared with reported adults of varying African ancestry and Sephardic Jewish neonates. Among 88 Nigerian neonates, $(\mathrm{TA})_{6}$ and $(\mathrm{TA})_{7}$ alleles were almost equally distributed $\left(0.46\right.$ and 0.43 , respectively). Some individuals with $(\mathrm{TA})_{5}$ and $(\mathrm{TA})_{8}$ sequences were encountered. Allele distribution was similar to that of the African ancestry population but differed from the Sephardic Jewish newborns, in whom the $(\mathrm{TA})_{6} /(\mathrm{TA})_{7}$ distribution was $0.65 /$ 0.35 . Whereas $45 \%$ of Nigerian alleles and $50 \%$ of African ancestry alleles, respectively, included a $(\mathrm{TA})_{7}$ or $(\mathrm{TA})_{8}$ sequence, only $35 \%$ of Jewish alleles were $(\mathrm{TA})_{7}(p<0.001)$, and no (TA $)_{8}$ alleles were encountered. The high frequency of (TA) $)_{n}$ promoter polymorphism, coupled with G-6-PD deficiency, may contribute to the pathogenesis of extreme neonatal hyperbilirubinemia in Nigeria. (Pediatr Res 63: 109-111, 2008)
\end{abstract}

$\mathrm{N}$ igerian neonates are affected by a high incidence of severe hyperbilirubinemia, bilirubin encephalopathy, and hyperbilirubinemia-associated mortality (1). Many of these cases occur in neonates who are also glucose-6phosphate dehydrogenase (G-6-PD) deficient. In G-6-PD deficient (Mediterranean mutation) neonates, an interaction has been described by which the incidence of neonatal hyperbilirubinemia is increased because of the presence, either in its heterozygous or homozygous form, of the $(\mathrm{TA})_{7}$ promoter sequence of the UDP-glucuronosyltransferase $1 \mathrm{~A} 1$ gene (UGT1Al) (2). This gene encodes the bilirubin conjugating enzyme, UDP-glucuronosyltransferase isoform 1A1 (UGT1A1) (3). In Caucasian populations, the usual (wildtype) form of the gene promoter contains a TATAA box with

Received June 4, 2007; accepted August 16, 2007.

Correspondence: Michael Kaplan, Department of Neonatology, Shaare Zedek Medical Center, P.O. Box 3235, Jerusalem 91031, Israel; e-mail: kaplan@cc.huji.ac.il

This study was supported in part by a grant from the Golden Charitable Trust, UK, for research in neonatal jaundice. a sequence of six thymine-adenine repeats $\left[(\mathrm{TA})_{6}\right]$ and coexists with the $(\mathrm{TA})_{7}$ polymorphism in a ratio of approximately $2 / 3: 1 / 3$. This mutation is also known as UGTIAI*28 and, in adults, in its homozygous form, is associated with Gilbert syndrome $(4,5)$. Because both $(\mathrm{TA})_{5}$ and $(\mathrm{TA})_{8}$ sequences may occasionally be encountered, we also use the designation $(\mathrm{TA})_{\mathrm{n}}$ in this report, where ${ }_{\mathrm{n}}$ refers to the number of (TA) repeats. In contrast with Caucasians, in a study of individuals of varying African descent, it was demonstrated that the (TA) 6 and $(\mathrm{TA})_{7}$ alleles were distributed almost equally $(0.43$ and 0.47 , respectively) (6). It appeared likely, therefore, that an increased $(\mathrm{TA})_{7}$ allele frequency would be found in indigenous Nigerians as well. Preponderance of this allele might exacerbate the intensity of the interaction with G-6-PD deficiency, thereby possibly predisposing to the high incidence of extreme hyperbilirubinemia in these neonates.

Our objective in the current study was to determine the $(\mathrm{TA})_{\mathrm{n}}$ allele distribution in a cohort of indigenous Nigerian newborns. To our knowledge, this allele frequency has not been determined in native Africans.

\section{METHODS}

The study was approved by the Institutional Review Boards of the Eku Baptist Hospital, Eku, and the Jos University Teaching Hospital, Jos, both in Nigeria. Both boards waived the need for obtaining informed consent. The subjects for this study comprised consecutively delivered, term, otherwise healthy neonates who were born at these hospitals. After delivery of the baby and placenta, blood was collected from the umbilical cord and stored in the form of dried blood spots on Guthrie paper. These blood samples were shipped to the Shaare Zedek Medical Center in Jerusalem, Israel for extraction of DNA and analysis of the UGT1A1 (TA) n promoter polymorphism.

Laboratory methods. DNA was extracted from $3.5 \mathrm{~mm}$ punches of the blood spots using a high salt extraction technique (7). UGT promoter genotypes were determined on a Prism 3100 Genetic Analyzer (Applied Biosystems, Foster City, CA) by size discrimination using 5' - fluorescently labeled polymerase chain reaction (PCR) primers surrounding the (TA) polymorphism and analyzed using GeneScan (Applied Biosystems) software. PCR was carried out using the primers gilb 55F: 6FAM-TGGATCCTGAGGTTCTGGAAGT, and gilb 415R: cagcatgggacaccactgg (Applied Biosystems) at an annealing temperature of $54^{\circ} \mathrm{C}$ for 35 cycles in a buffer containing $1.5 \mathrm{mM}$ $\mathrm{MgCl}_{2}$. Fragment size was correlated with the (TA) $)_{\mathrm{n}}$ polymorphism and verified by sequencing a selected set of fragments.

\footnotetext{
Abbreviations: G-6-PD, glucose-6-phosphate dehydrogenase; STB, serum total bilirubin; UGT1A1, UDP-glucuronosyltransferase isoform 1A1; UGT1A1, gene encoding the enzyme UGT1A1
} 
Data analysis. Allele distribution of the various UGT promoter (TA) sequences, including $(\mathrm{TA})_{5},(\mathrm{TA})_{6},(\mathrm{TA})_{7}$, and $(\mathrm{TA})_{8}$, was determined. Similarly, the various UGT promoter genotypes, comprised of combinations of $(\mathrm{TA})_{\mathrm{n}}$ alleles, were established. These gene distributions were compared with previously reported adults from North and Central America who had varying degrees of African ancestry, on the one hand (6), and previously reported Sephardic Jewish neonates, on the other $(8,9)$. The Sephardic Jewish studies had been analyzed in the same Jerusalem laboratory as were the Nigerians. Allele and genotype frequencies were compared between the population groups using $\chi^{2}$ analysis.

\section{RESULTS}

Dried blood spots were received from a convenience sample of 88 Nigerian-born neonates. Of 176 possible (TA) alleles, 12 were $(\mathrm{TA})_{5}$ (allele frequency 0.07), $82(\mathrm{TA})_{6}(0.46)$, and 78 $(\mathrm{TA})_{7}(0.44)$. Four alleles were $(\mathrm{TA})_{8}(0.02)$ (Table 1$)$. Genotype distribution is summarized in Table 2 .

In contrast with the Sephardic Jewish population in which the $(\mathrm{TA})_{6}$ allele was clearly the wild type and comprised two thirds of these alleles, in both indigenous and African ancestry populations, the (TA) 6 and (TA) $)_{7}$ alleles were almost equally represented. Neither $(\mathrm{TA})_{5}$ nor $(\mathrm{TA})_{8}$ alleles were found in the Jewish group. Whereas $45 \%$ of Nigerian alleles and $50 \%$ of African ancestry alleles had a (TA) sequence of $(\mathrm{TA})_{7}$ or $(\mathrm{TA})_{8}$, only $35 \%$ of Jewish alleles were $(\mathrm{TA})_{7}(p<0.001)$, and no $(\mathrm{TA})_{8}$ alleles were encountered. Similarly, the combined number of Nigerian and African ancestry individuals with a (TA) promoter genotype of $(\mathrm{TA})_{7} /(\mathrm{TA})_{7}$ or larger was

Table 1. (TA) ${ }_{n}$ UGT promoter sequence allele distribution among the indigenous Nigerian neonates

\begin{tabular}{lcccc}
\hline & \multicolumn{4}{c}{$(\mathrm{TA})_{\mathrm{n}}$ Allele frequency } \\
\cline { 2 - 5 } Population (no. of individuals) & $(\mathrm{TA})_{5}$ & $(\mathrm{TA})_{6}$ & $(\mathrm{TA})_{7}$ & $(\mathrm{TA})_{8}$ \\
\hline Indigenous Nigerian (88) & 0.07 & 0.46 & 0.44 & 0.02 \\
African descent (101) & 0.04 & 0.47 & 0.43 & 0.07 \\
Sephardic Jewish (262) & - & 0.65 & 0.35 & - \\
\hline
\end{tabular}

Previously reported studies of individuals of African descent (6) and Sephardic Jewish $(8,9)$ neonates are included for reference and comparison. Whereas the $(\mathrm{TA})_{6}$ and $(\mathrm{TA})_{7}$ allele distribution was similar in both indigenous Nigerian and varying African descent groups, there was a clear preponderance (wild type) of (TA) 6 alleles in the Sephardic Jewish group.

Table 2. Genotype distribution of $(T A)_{n}$ UGT1A1 promoter polymorphism among indigenous Nigerian-born neonates $(n=88)$ compared with previously reported individuals of varying African ancestry (6) and Sephardic Jewish neonates $(8,9)$

Number of individuals $(\%)$

\begin{tabular}{cccc}
\cline { 2 - 4 } Genotype & $\begin{array}{c}\text { Indigenous } \\
\text { Nigerian }\end{array}$ & $\begin{array}{c}\text { Varying African } \\
\text { ancestry }\end{array}$ & $\begin{array}{c}\text { Sephardic } \\
\text { Jewish }\end{array}$ \\
\hline$(\mathrm{TA})_{5} /(\mathrm{TA})_{5}$ & $1(1.1)$ & - & - \\
$(\mathrm{TA})_{5} /(\mathrm{TA})_{6}$ & $5(5.7)$ & $2(2)$ & - \\
$(\mathrm{TA})_{5} /(\mathrm{TA})_{7}$ & $5(5.7)$ & $5(5)$ & - \\
$(\mathrm{TA})_{6} /(\mathrm{TA})_{8}$ & $1(1)$ & $4(4)$ & - \\
$(\mathrm{TA})_{6} /(\mathrm{TA})_{6}$ & $19(21.6)$ & $26(26)$ & $116(44.3)$ \\
$(\mathrm{TA})_{6} /(\mathrm{TA})_{7}$ & $38(43.2)$ & $37(37)$ & $110(42)$ \\
$(\mathrm{TA})_{7} /(\mathrm{TA})_{7}$ & $16(18.2)$ & $19(19)$ & $36(13.7)$ \\
$(\mathrm{TA})_{7} /(\mathrm{TA})_{8}$ & $3(3.4)$ & $6(6)$ & - \\
$(\mathrm{TA})_{8} /(\mathrm{TA})_{8}$ & - & $2(2)$ & - \\
Total number of & & 101 & 262 \\
individuals: 88 & & & \\
\hline
\end{tabular}

greater than that of the Jewish population group [46/189 $(24.3 \%)$ vs $36 / 262(13.7 \%), p=0.006]$.

\section{DISCUSSION}

The serum total bilirubin (STB) concentration, at any point in time, represents the contributing forces of bilirubin production, primarily from the catabolism of heme, on the one hand, and the elimination of bilirubin from the body, primarily by hepatic conjugation and subsequent excretion, on the other (10). As long as there is equilibrium between these processes, the STB should remain within the physiologic range and not pose a danger (11). However, bilirubin production-elimination imbalance may lead to excessive accumulation of bilirubin with resultant hyperbilirubinemia. The bilirubin conjugation process is governed in the hepatocyte by the conjugating enzyme UGT1A1. The most common form (wild type) of the encoding UGTIAl gene contains a sequence (TA) ${ }_{6}$ TAA in the TATAA box of its promoter [(TA $)_{6}$, in brief] (3). Insertion of additional (TA) sequences, resulting in a (TA $)_{7}$ or occasionally $(\mathrm{TA})_{8}$ sequence, causes progressively diminished expression of the UGTIAl promoter (6). Because the coding area of the gene is unaffected, the UGT1A1 enzyme itself will be normally structured. However, the decreased promoter expression results in less protein and, therefore, lower enzymatic activity. Adults with Gilbert syndrome have been demonstrated to be homozygous for the $(\mathrm{TA})_{7}$ promoter allele $(4,5)$.

Previous studies have shown a propensity for diminished bilirubin conjugation in the pathophysiology of neonatal jaundice in G-6-PD deficient neonates compared with G-6-PD normal controls (12). This was determined to be the result of interaction between G-6-PD deficiency and the (TA) UGTIA1 promoter sequence, both in its heterozygous and homozygous forms. Combination of the (TA $)_{7}$ sequence and G-6-PD deficiency increased the incidence of neonatal hyperbilirubinemia, defined as any STB concentration of 15.0 $\mathrm{mg} / \mathrm{dL}$ or greater, in a stepwise, allele dose-related fashion (2). Interestingly, in the absence of G-6-PD deficiency, the (TA) allele did not act as a risk factor, and, conversely, in the absence of the (TA) 7 polymorphism, G-6-PD deficiency did not act as a risk factor for hyperbilirubinemia. In the steady state, the (TA) ${ }_{7}$ mutation, rather than increased hemolysis, has been demonstrated to have a fundamental role in determining higher STB concentrations in G-6-PD deficient (TA) $)_{7} /(\mathrm{TA})_{7}$ homozygotes compared with $(\mathrm{TA})_{6} /(\mathrm{TA})_{6}$ homozygote or $(\mathrm{TA})_{6} /(\mathrm{TA})_{7}$ heterozygote counterparts (9).

Because (TA) ${ }_{7}$ UGT1A1 promoter polymorphism potentiates hyperbilirubinemia in neonates with G-6-PD deficiency, we asked whether the allele frequency of the mutant UGT1A1 gene promoter might be higher in the Nigerian population than in Caucasians, explaining, at least in part, the high incidence of bilirubin-associated mortality and morbidity among Nigerian neonates. The only study among related population groups of which we are aware is the above-mentioned report of Beutler et al. (6). These authors determined the (TA) distribution among Central and North American individuals of varying degrees of African ancestry. Although STB concentrations were not available for these individuals, UGT1A1 
promoter allele frequency greater than (TA) 6 was found in $50 \%$ of tested individuals. This would be expected to diminish gene expression, diminish enzyme activity, and increase the STB concentration, compared with Caucasian counterparts. Because the distribution of $(\mathrm{TA})_{6},(\mathrm{TA})_{7}$, and (TA) 8 alleles in the African ancestry individuals may have been altered by intermarriage, we predicted that, in indigenous Nigerians, an even greater preponderance of $(\mathrm{TA})_{7}$ and $(\mathrm{TA})_{8}$ alleles than that of the African Americans of varying ancestry may be found. However, although the Nigerian (TA $)_{7}$ allele frequency did contrast with the distribution in Caucasian populations, their $(\mathrm{TA})_{\mathrm{n}}$ distribution was similar to that of the varying ancestry Africans, suggesting a minimal role of intermarriage in moderating the allele distribution.

G-6-PD deficient neonates have both an inherent degree of increased bilirubin production and a predisposition to diminished bilirubin conjugation (12-14). The combination of these processes may lead to bilirubin production-conjugation imbalance, with the potential of hyperbilirubinemia (15). In most cases, this hyperbilirubinemia is moderate and responds to phototherapy. In extreme cases, a chemical or infective trigger may stimulate hemolysis. When this process acts on the backdrop of already increased hemolysis and diminished bilirubin conjugation, extreme hyperbilirubinemia may result. We suggest that the greater allele frequency of $(\mathrm{TA})_{7}$ and $(\mathrm{TA})_{8}$ alleles in G-6-PD deficient Nigerian neonates might further increase this inherent imbalance between bilirubin production and conjugation. Any additional lack of equilibrium such as sudden increased hemolysis or further conjugation deficiency (e.g., prematurity) may potentiate extreme hyperbilirubinemia, with the potential of bilirubin-associated morbidity or mortality.

G-6-PD deficiency plays a major role in the pathogenesis of severe neonatal hyperbilirubinemia in Nigeria. Slusher et al. (1) found that $31 \%$ of 45 clinically jaundiced infants were G-6-PD deficient, of whom $36 \%$ died of presumed kernicterus. Similarly, Owa (16) reported that $62.3 \%$ of 106 severely jaundiced Nigerian neonates were G-6-PD deficient compared with $13.3 \%$ of 128 nonjaundiced controls. Despite their higher frequency of the (TA) 7 promoter polymorphism, African American neonates, overall, have a lower prevalence of neonatal jaundice compared with Caucasian counterparts (17). However, within the African-American neonatal group is a subgroup of G-6-PD deficient infants with a high incidence of neonatal hyperbilirubinemia (14). Most likely, coupling of genetic factors, including G-6-PD deficiency and (TA) 7 promoter polymorphism, leads to neonatal hyperbilirubinemia rather than any either of these factors individually.

Our findings may have further-reaching implications as well. Of 125 neonates recently reported from the U.S. based Pilot Kernicterus Registry, both African-American background as well as G-6-PD deficiency were overrepresented relative to their expected frequency in the overall U.S. population (18). Frequently, G-6-PD deficiency and African-
American ethnicity were encountered in combination. Because $11-13 \%$ of African Americans are G-6-PD deficient $(14,19-22)$, and the ancestry of many can be presumed to be West African, the mechanism proposed for hyperbilirubinemia in G-6-PD deficient Nigerian neonates may also be contributory to that of G-6-PD deficient African-American infants in the United States.

\section{REFERENCES}

1. Slusher TM, Vreman HJ, McLaren DW, Lewison LJ, Brown AK, Stevenson DK 1995 Glucose-6-phosphate dehydrogenase deficiency and carboxyhemoglobin concentrations associated with bilirubin-related morbidity and death in Nigerian infants. J Pediatr 126:102-108

2. Kaplan M, Renbaum P, Levy-Lahad E, Hammerman C, Lahad A, Beutler E 1997 Gilbert syndrome and glucose-6-phosphate dehydrogenase deficiency: a dosedependent genetic interaction crucial to neonatal hyperbilirubinemia. Proc Natl Acad Sci U S A 94:12128-12132

3. Kaplan M, Hammerman C, Maisels MJ 2003 Bilirubin genetics for the nongeneticist: hereditary defects of neonatal bilirubin conjugation. Pediatrics 111:886-893

4. Bosma PJ, Chowdhury JR, Bakker C, Gantla S, de Boer A, Oostra BA, Lindhout D, Tytgat GN, Jansen PL, Oude Elferink RP, Chowdhury NR 1995 The gene basis of the reduced expression of bilirubin UDP-glucuronosyltransferase 1 in Gilbert's syndrome. N Engl J Med 333:1171-1175

5. Monaghan G, Ryan M, Seddon R, Hume R, Burchell B 1996 Genetic variation in bilirubin UDP-glucuronosyltransferase gene promoter and Gilbert's syndrome. Lancet 347:578-581

6. Beutler E, Gelbart T, Demina A 1998 Racial variability in the UDP-glucuronosyltransferase 1 (UGT1A1) promoter: a balanced polymorphism for regulation of bilirubin metabolism? Proc Natl Acad Sci USA 95:8170-8174

7. Miller SA, Dykes DD, Polesky HF 1988 A simple salting out procedure for extracting DNA from human nucleated cells. Nucleic Acids Res 16:1215

8. Kaplan M, Hammerman C, Rubaltelli FF, Vilei MT, Levy-Lahad E, Renbaum P, Vreman HJ, Stevenson DK, Muraca M 2002 Hemolysis and bilirubin conjugation in association with UDP-glucuronosyltransferase $1 \mathrm{~A} 1$ promoter polymorphism. Hepatology 35:905-911

9. Kaplan M, Renbaum P, Vreman HJ, Wong RJ, Levy-Lahad E, Hammerman C, Stevenson DK 2007 (TA)n UGT 1A1 promoter polymorphism: A crucial factor in the pathophysiology of jaundice in G-6-PD-deficient neonates. Pediatr Res 61:727731

10. Dennery PA, Seidman DS, Stevenson DK 2001 Neonatal hyperbilirubinemia. N Engl J Med 344:581-590

11. Kaplan M, Muraca M, Hammerman C, Rubaltelli FF, Vilei MT, Vreman HJ, Stevenson DK 2002 Imbalance between production and conjugation of bilirubin: a fundamental concept in the mechanism of neonatal jaundice. Pediatrics 110:e47

12. Kaplan M, Rubaltelli FF, Hammerman C, Vilei MT, Leiter C, Abramov A, Muraca M 1996 Conjugated bilirubin in neonates with glucose-6-phosphate dehydrogenase deficiency. J Pediatr 128:695-697

13. Kaplan M, Vreman HJ, Hammerman C, Leiter C, Abramov A, Stevenson DK 1996 Contribution of haemolysis to jaundice in Sephardic Jewish glucose-6-phosphate dehydrogenase deficient neonates. Br J Haematol 93:822-827

14. Kaplan M, Herschel M, Hammerman C, Hoyer JD, Stevenson DK 2004 Hyperbilirubinemia among African American, glucose-6-phosphate dehydrogenase-deficient neonates. Pediatrics 114:e213-e219

15. Kaplan M, Muraca M, Vreman HJ, Hammerman C, Vilei MT, Rubaltelli FF, Stevenson DK 2005 Neonatal bilirubin production-conjugation imbalance: effect of glucose-6-phosphate dehydrogenase deficiency and borderline prematurity. Arch Dis Child Fetal Neonatal Ed 90:F123-F127

16. Owa JA 1989 Relationship between exposure to icterogenic agents, glucose-6phosphate dehydrogenase deficiency and neonatal jaundice in Nigeria. Acta Paediatr Scand 78:848-852

17. Linn S, Schoenbaum SC, Monson RR, Rosner B, Stubblefield PG, Ryan KJ 1985 Epidemiology of neonatal hyperbilirubinemia. Pediatrics 75:770-774

18. Bhutani VK, Johnson LH, Jeffrey Maisels M, Newman TB, Phibbs C, Stark AR, Yeargin-Allsopp M 2004 Kernicterus: epidemiological strategies for its prevention through systems-based approaches. J Perinatol 24:650-662

19. Tarlov AR, Brewer GJ, Carson PE, Alving AS 1962 Primaquine sensitivity. Glucose-6-phosphate dehydrogenase deficiency: an inborn error of metabolism of medical and biological significance. Arch Intern Med 109:209-234

20. Heller P, Best WR, Nelson RB, Becktel J 1979 Clinical implications of sickle-cell trait and glucose-6-phosphate dehydrogenase deficiency in hospitalized black male patients. N Engl J Med 300:1001-1005

21. O'Flynn ME, Hsia DY 1963 Serum bilirubin levels and glucose 6 phosphate dehydrogenase deficiency in newborn American Negroes. J Pediatr 63:160-161

22. Chinevere TD, Murray CK, Grant E, Jr. Johnson GA, Duelm F, Hospenthal DR 2006 Prevalence of glucose-6-phosphate dehydrogenase deficiency in U.S. Army personnel. Mil Med 171:905-907 